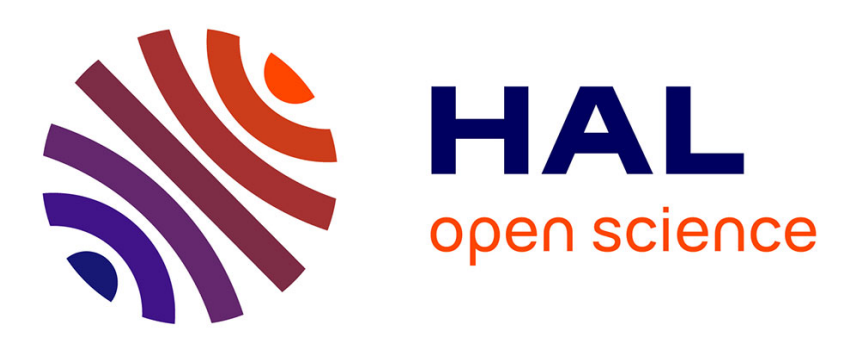

\title{
Borrelia crocidurae infection of Ornithodoros erraticus (Lucas, 1849) ticks in Tunisia.
}

Ali Bouattour, Martine Garnier, Youmna M'Ghirbi, M'Hammed Sarih, Lise Gern, Elisabeth Ferquel, Danièle Postic, Muriel Cornet

\section{To cite this version:}

Ali Bouattour, Martine Garnier, Youmna M'Ghirbi, M'Hammed Sarih, Lise Gern, et al.. Borrelia crocidurae infection of Ornithodoros erraticus (Lucas, 1849) ticks in Tunisia.. Vector-Borne and Zoonotic Diseases, 2010, 10 (9), pp.825-30. 10.1089/vbz.2009.0151 . pasteur-00620982

\section{HAL Id: pasteur-00620982 https://hal-riip.archives-ouvertes.fr/pasteur-00620982}

Submitted on 26 Sep 2011

HAL is a multi-disciplinary open access archive for the deposit and dissemination of scientific research documents, whether they are published or not. The documents may come from teaching and research institutions in France or abroad, or from public or private research centers.
L'archive ouverte pluridisciplinaire HAL, est destinée au dépôt et à la diffusion de documents scientifiques de niveau recherche, publiés ou non, émanant des établissements d'enseignement et de recherche français ou étrangers, des laboratoires publics ou privés. 


\title{
Borrelia crocidurae Infection of Ornithodoros erraticus (Lucas, 1849) Ticks in Tunisia
}

\author{
Ali Bouattour, ${ }^{1}$ Martine Garnier, ${ }^{2}$ Youmna M'Ghirbi, ${ }^{1}$ M'hammed Sarih, ${ }^{3}$ Lise Gern, ${ }^{4}$ \\ Elisabeth Ferquel, ${ }^{2}$ Danièle Postic, ${ }^{2}$ and Muriel Cornet ${ }^{2,5}$
}

\begin{abstract}
Tick-borne relapsing fever (TBRF) is caused by Borrelia species transmitted to humans by infected Ornithodoros sp. ticks. The disease has been rarely described in North Africa, and in Tunisia the local transmission of TBRF seems to have disappeared or is undiagnosed. A longitudinal study was conducted in 14 sites located in four different bioclimatic zones of Tunisia to assess both the distribution of Ornithodoros sp. and their infection rate with the relapsing fever Borrelia sp. Three polymerase chain reaction methods targeting the 16S rRNA, the intergenic spacer, and the fla (flagellin) genes were used and phylogenetic analyses were carried out. Three hundred and fifty-eight specimens of Ornithodoros were collected: O. erraticus (previously termed "small variety") $(n=190)$ and O. normandi $(n=168)$. Borrelia crocidurae DNA was detected in $15.1 \%$ of O. erraticus (small variety) (24 out of the 159 randomly selected for testing) collected in rodent burrows situated in the arid and Saharan areas in southern Tunisia. Molecular analysis targeting the 16S rRNA gene and the noncoding intergenic spacer domain showed good resolution for this Borrelia sp., although no molecular polymorphism was evidenced according to location. In contrast, none of the $133 \mathrm{O}$. normandi, also randomly selected for testing, was infected by Borrelia sp. and these ticks were restricted to the subhumid and semiarid zones in northern Tunisia. Both O. erraticus (small variety) and O. normandi were found in Tunisia and the high B. crocidurae infection rate found in O. erraticus highlights the risk of TBRF transmission in the southern part of the country.
\end{abstract}

Key Words: Borrelia crocidurae-Ornithodoros—Tick-borne relapsing fever-Tunisia.

\section{Introduction}

$\mathbf{T}$ ICK-BORNE RELAPSING FEVER (TBRF) is caused by several Borrelia species and transmitted by Argasid soft ticks of the genus Ornithodoros. This genus comprises about 100 species (Hoogstraal 1985) that are mostly geographically restricted and are considered to be specific vectors of a given Borrelia sp. As Borrelia sp. may persist for many years in their long-lived vectors, Ornithodoros sp. are considered as both vectors and reservoirs (Parola and Raoult 2001). Vertebrate reservoirs include a variety of mammals, mainly rodents, inhabiting burrows, dens, or caves. Humans are infected while in contact with Ornithodoros sp. in infested areas. TBRF occurs in all continents, except Antarctica and Australia, and may cause a serious disease with neurological, ocular, or reproductive complications if untreated (Cutler 2006, Cutler et al. 2009). The reported mortality rate is up to $5 \%$ and the severity of the disease varies according to the species: Borrelia duttonii being associated with greater severity than Borrelia crocidurae (Cutler 2006, Cutler et al. 2009). TBRF is endemic in Africa and is highly prevalent in central, eastern, and southern Africa, where it is due to B. duttonii and transmitted by Ornithodoros moubata and Ornithodoros porcinus (Hoogstraal 1985, Cutler 2006, Cutler et al. 2009). The disease is also endemic in western and Saharan African countries such as Mauritania, Senegal, Mali, and Chad, where it is due to B. crocidurae and transmitted by Ornithodoros sonrai (formerly genus Alectorobius) (Cutler et al. 2009). The rising incidence reported in these regions may be related to the climatic changes (Trape et al. 1991, 1996, Vial et al. 2006). In Northwest Africa, B. crocidurae (including the possibly synonymous Borrelia merionesi and Borrelia microti)

\footnotetext{
${ }^{1}$ Service d'Entomologie Médicale, Institut Pasteur de Tunis, Tunis, Tunisia.

${ }^{2}$ Centre National de Référence des Borrelia, Institut Pasteur, Paris, France.

${ }^{3}$ Unité des Maladies Vectorielles, Institut Pasteur de Casablanca, Casablanca, Maroc.

${ }^{4}$ Laboratoire d'Eco-Epidémiologie des Parasites, Institut de Biologie, Université de Neuchâtel, Suisse.

${ }^{5}$ Laboratoire de Microbiologie, Hôtel-Dieu, AP-HP, Université Paris Descartes, Paris, France.
} 
is transmitted by Ornithodoros erraticus previously termed as "small variety" of O. erraticus (Morel 1965, Hoogstraal 1985, Stanek 1995) and Borrelia hispanica is maintained by Ornithodorus marocanus, which is often reported as O. erraticus large variety (Hoogstraal 1985, Stanek 1995). In Tunisia, since the first human case of TBRF reported by Nicolle in 1931 (Nicolle et al. 1932), the disease has been neglected and recent epidemiological data are lacking. Local transmission of TBRF seems to have disappeared or is undiagnosed.

We conducted a longitudinal study to assess both the distribution of Ornithodoros sp. in Tunisia and their infection rate by relapsing fever Borrelia sp. Because of fastidious culture requirements, we used recently developed molecular methods that lead to rapid detection and identification of relapsing fever Borrelia sp. in vertebrates and vectors (Cutler et al. 1994, Marti Ras et al. 1996, Fukunaga et al. 2001, Wyplosz et al. 2005, Assous et al. 2006).

\section{Materials and Methods}

\section{Collection and identification of Ornithodoros ticks}

Our study was conducted between March 2005 and July 2006, in 14 sites located in four different bioclimatic zones of Tunisia (Table 1). As Ornithodoros sp. are endophilic ticks inhabiting small mammal burrows, the sites were selected on the basis of the presence of such burrows, mainly occupied by jird (Meriones shawi), gerbil (Gerbillus campestre), and the fat sand rat (Psammomys obesus) (Bernard 1970). In each site, burrows were randomly selected, regardless of their activity, because Ornithodoros sp. are able to survive for long periods, even up to 5 years, in the absence of their hosts. Burrows were opened to the nest, using a pickaxe. Nest soil samples were sieved through wire mesh to eliminate debris and then exposed to sunlight on a sorting tray. All ticks collected were stored into flasks containing $70 \%$ ethanol until identification and DNA extraction. For identification, we used the description of Colas-Belcour (1930) based on the camerostomal folds and the drawing of the dorsal surface (or integument) of the body. The morphology of the coxae 1 was used as an additional criterion (Fig. 1). The sex and developmental stage were determined for each tick.

\section{DNA extraction and polymerase chain reaction methods}

Tick DNA was extracted using the QIAmp DNA Mini Kit (Qiagen, Hilden, Germany) according to the manufacturer's instructions. DNA was eluted in $100 \mu \mathrm{L}$ of ADMH Tris-HCL; $0.5 \mathrm{mM}$ EDTA PH 9.0 (AE) buffer and stored at $-20^{\circ} \mathrm{C}$ until amplification. Three polymerase chain reaction (PCR) protocols were used to detect relapsing fever Borrelia DNA in ticks. First, a seminested protocol targeting the entire 16S rRNA gene and using the outer primers fD3 and T50 was carried out, as previously described (Marti Ras et al. 1996). The inner primers were REC4, as previously described (Marti Ras et al. 1996), and RF16SR (5' pos 867-AGGCGCCACACTTAA CACGT-3'pos 847). REC4 and RF16SR were paired with T50 and fD3, respectively, to obtain two amplicons with a $208 \mathrm{bp}$ overlap. These two contigs were aligned to obtain the sequence of the entire 16S rRNA gene $(1.5 \mathrm{~kb}$ long) (Sarih et al. 2009). Second, a nested protocol targeting the large noncoding intergenic spacer (IGS) between the 16S and 23S rRNA genes was used (Bunikis et al. 2004). The third PCR method was a classic single PCR targeting the flaB (flagellin) gene (Assous et al. 2006). The PCR products were revealed by electrophoresis in a $0.8 \%$ agarose gel in Tris-borate-EDTA (TBE), stained with ethidium bromide.

\section{Sequence alignment and phylogenetic relationships}

Amplification PCR products were sequenced by Genome Express (Meylan, France) using the same oligonucleotides as for PCR (Marti Ras et al. 1996, Bunikis et al. 2004, Assous et al. 2006, Sarih et al. 2009). All the sequences determined in this study were submitted to GenBank (accession numbers for the IGS are from GQ358160 to GQ358180 and for the 16S rRNA are from GQ358181 to GQ358200). The CLUSTAL X

Table 1. Ornithodoros Species ANd Borrelia CROCIDURAe INFEction In Tunisia

\begin{tabular}{|c|c|c|c|c|c|c|c|}
\hline Site (no.) & $\begin{array}{c}\text { Bioclimatic } \\
\text { zone }\end{array}$ & $\begin{array}{c}\text { Coordinates } \\
\text { North }\end{array}$ & $\begin{array}{c}\text { Coordinates } \\
\text { West }\end{array}$ & $\begin{array}{l}\text { Number of } \\
\text { burrows } \\
\text { examined }\end{array}$ & $\begin{array}{l}\text { Ornithodoros } \\
\text { normandi Total } \\
(N / M / F)^{\mathrm{a}}\end{array}$ & $\begin{array}{c}\text { Ornithodoros } \\
\text { erraticus Total } \\
(N / M / F)^{\mathrm{a}}\end{array}$ & $\begin{array}{l}\text { O. erraticus } \\
\text { positive for } \\
\text { Borrelia/ticks } \\
\text { tested }(\%)\end{array}$ \\
\hline Jbel El Hnoucha (1) & Subhumid & $37^{\circ} 00^{\prime} 90,8^{\prime \prime}$ & $09^{\circ} 43^{\prime} 08,1^{\prime \prime}$ & 10 & $64(46 / 1 / 17)$ & $6(3 / 1 / 2)$ & $0 / 6$ \\
\hline Sabâ El Aouinet (2) & Subhumid & $36^{\circ} 59^{\prime} 72,2^{\prime \prime}$ & $09^{\circ} 46^{\prime} 44,7^{\prime \prime}$ & 5 & $29(21 / 4 / 4)$ & 0 & 0 \\
\hline Oued Remel (3) & Semiarid & $36^{\circ} 06^{\prime} 92,2^{\prime \prime}$ & $08^{\circ} 38^{\prime} 31,24^{\prime \prime}$ & 7 & $34(19 / 9 / 6)$ & 0 & 0 \\
\hline Oued Errebh (4) & Semiarid & $36^{\circ} 24^{\prime} 51,74^{\prime \prime}$ & $10^{\circ} 08^{\prime} 08,45^{\prime \prime}$ & 7 & $41(26 / 9 / 6)$ & 0 & 0 \\
\hline Hanchir el Ghort (5) & Semiarid & $36^{\circ} 33^{\prime} 02,4^{\prime \prime}$ & $10^{\circ} 36^{\prime} 39,72^{\prime \prime}$ & 7 & 0 & 0 & 0 \\
\hline Forêt Dar Chichou (6) & Subhumid & $36^{\circ} 58^{\prime} 080^{\prime \prime}$ & $10^{\circ} 59^{\prime} 75,2^{\prime \prime}$ & 7 & 0 & 0 & 0 \\
\hline Echahda El Gharbia (7) & Arid & $35^{\circ} 16^{\prime} 13,5^{\prime \prime}$ & $10^{\circ} 14^{\prime} 12,3^{\prime \prime}$ & 5 & 0 & $25(19 / 4 / 2)$ & $5 / 23(21.7)$ \\
\hline Sabkhet El Khsima (8) & Arid & $35^{\circ} 33^{\prime} 08,8^{\prime \prime}$ & $10^{\circ} 12^{\prime} 72,8^{\prime \prime}$ & 5 & 0 & $4(2 / 1 / 1)$ & $1 / 4(25)$ \\
\hline Sabkhet Bhir (9) & Arid & $35^{\circ} 14^{\prime} 73,6^{\prime \prime}$ & $09^{\circ} 45^{\prime} 38,4^{\prime \prime}$ & 15 & 0 & $65(36 / 12 / 17)$ & $9 / 56(16.1)$ \\
\hline Sebket Echrita (10) & Arid & $35^{\circ} 16^{\prime} 13,0^{\prime \prime}$ & $10^{\circ} 14^{\prime} 20,8^{\prime \prime}$ & 7 & 0 & $15(10 / 4 / 1)$ & $2 / 14(14.3)$ \\
\hline Jelma (11) & Arid & $35^{\circ} 14^{\prime} 02,92^{\prime \prime}$ & $09^{\circ} 27^{\prime} 42,54^{\prime \prime}$ & 6 & 0 & 0 & 0 \\
\hline El Guettar (12) & Arid & $34^{\circ} 18^{\prime} 10,27^{\prime \prime}$ & $08^{\circ} 59^{\prime} 32,10^{\prime \prime}$ & 11 & 0 & $46(38 / 4 / 4)$ & $4 / 35(11.4)$ \\
\hline Limaguess (13) & Saharian & $33^{\circ} 45^{\prime} 57,51^{\prime \prime}$ & $09^{\circ} 05^{\prime} 02,22^{\prime \prime}$ & 8 & 0 & $29(25 / 4 / 0)$ & $3 / 21(14.3)$ \\
\hline Djemna (14) & Saharian & $33^{\circ} 34^{\prime} 54,34^{\prime \prime}$ & $09^{\circ} 00^{\prime} 58,71^{\prime \prime}$ & 8 & 0 & 0 & 0 \\
\hline Total & & & & 108 & 168 & 190 & 24/159 (15.1) \\
\hline
\end{tabular}

${ }^{\mathrm{a}} \mathrm{Nymph} / \mathrm{males} /$ females. 


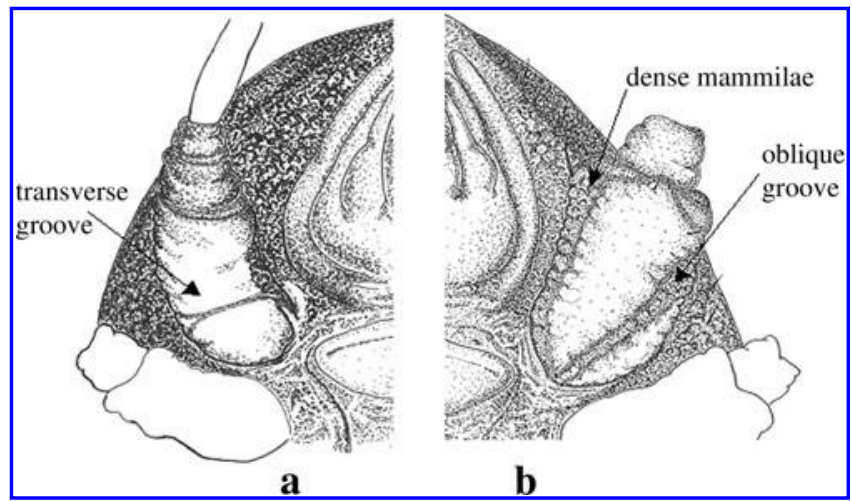

FIG. 1. Diagram of coxae I: (a) Ornithodoros normandi, (b) Ornithodoros erraticus (drawn by the author).

(Thompson et al. 1997) algorithm was used for sequence alignments and MEGA 4.1 (Kumar et al. 1994) software for phylogenetic analyses. Distances were calculated using the Jukes and Cantor correction (Saitou and Nei 1987) in a pairwise deletion procedure. Sequences were then analyzed by the unweighted pair group with mathematical average (Sneath and Sokal 1962) for the construction of the phylogenetic trees.

\section{Results}

\section{Collected ticks}

Three hundred and fifty-eight Ornithodoros sp. were collected in the 108 burrows examined and ticks were found in 10 out of the 14 sites investigated, from a depth of $50 \mathrm{~cm}$ to $2 \mathrm{~m}$ (Table 1). Ticks belonged to the species O. erraticus (previously named small variety; Lucas 1845$)(n=190)$ and Ornithodoros normandi $(n=168)$ and details are presented in Table 1 . The distinction between these Ornithodoros sp. was based mainly on the features of the coxae 1 (the first segment of the leg), which presents a transverse groove in $O$. normandi, in contrast to an oblique one with a dense mammilae in $O$. erraticus (Fig. 1).

\section{Borrelia $s p$. detection in Ornithodoros sp. ticks}

Among the ticks collected, 159 O. erraticus (small variety) (111 nymphs, 22 males, and 26 females) and 133 O. normandi (90 nymphs, 15 males, and 28 females) were randomly selected and tested for Borrelia infection. Borrelia DNA was detected by both the $16 S$ and the IGS PCR in 24 O. erraticus, leading to an infection rate of $15.1 \%$. The fla PCR method was positive in only $50 \%$ of these samples. In contrast, no Borrelia DNA was detected from the 133 O. normandi tested. The infection rates of O. erraticus ticks were $11.7 \%$ for nymphs (13 positive out of 111), 27.3\% for males (6 positive out of 22 ), and $19.2 \%$ for females (5 positive out of 26 ). No significant difference was observed between the infection rates of adults and nymphs $\left(\chi^{2}=3.28 ; p=0.07\right)$ and between males and females $\left(\chi^{2}=0.44 ; p=0.5\right)$. The O. erraticus infected by Borrelia sp. were collected only in the arid and Saharan areas (site no. 7-10, 12, and 13 in Table 1), whereas no Borrelia DNA was detected in the ticks collected in the subhumid and semiarid areas in northern Tunisia, even in Jbel El Hnoucha (site no. 1 in Table 1) where O. erraticus ticks were found.
The entire 16S rRNA sequences were available from 20 out of the 24 PCR products obtained from O. erraticus (small variety) and B. crocidurae was identified from all these sequences by BLAST (Basic Local Alignment Search Tool) analyses. All 16S rRNA sequences were submitted to GenBank (accession no. GQ358181 to GQ358200). They demonstrated 99.93\% (1 nucleotide [nt] difference) to 100\% identity with B. crocidurae DQ057990 from GenBank. This polymorphism (1 nt difference) was illustrated on the phylogenetic tree by the shallow division in two close branches, which comprised all our B. crocidurae Tunisian sequences (Fig. 2). We noted only very small differences between African species, confirming previous results (for examples, 1 or 2 nt difference between our $B$. crocidurae Tunisian sequences and B. duttonii Ly AF107364, and 2 or 3 nt difference between B. crocidurae and B. hispanica DQ057988) (Scott et al. 2005, Wyplosz et al. 2005, Sarih et al. 2009) (Fig. 2). In the IGS analysis, all the 21 Borrelia sequences obtained from the Tunisian $O$. erraticus were grouped in a single cluster with the B. crocidurae DQ000287 (Fig. 3). These sequences were submitted to GenBank (accession no. GQ358160 to GQ358180). As expected, the IGS sequences showed larger intraspecies and interspecies polymorphisms than the $16 \mathrm{~S}$ rRNA sequences, with the exception of Borrelia recurrentis and B. duttonii East African species, which cannot be separated by their IGS sequence as previously shown (Scott et al. 2005). However, no molecular polymorphism according to the location has been observed among our $B$. crocidurae sequences (Figs. 2 and 3). Because of the inferior sensitivity of the fla PCR, only three fla sequences could be determined, leading to $B$. crocidurae identification.

\section{Discussion}

During our investigation, 108 burrows, in four bioclimatic zones of Tunisia, were opened and investigated for the presence of soft ticks of the genus Ornithodoros. We collected 358 Ornithodoros sp. belonging to O. normandi Larrousse and $O$. erraticus Lucas species. In agreement with Larrousse (1923), we found O. normandi only in the subhumid and semiarid zones. Thus, the distribution of this endemic species seems to be restricted to the north of Tunisia above the $400 \mathrm{~mm}$ isohyets. By contrast, O. erraticus was mainly collected in burrows situated in the arid and Saharan zones (Table 1). O. erraticus occurs in southwestern ex-USSR, the Middle East, and the Mediterranean Basin (Morel 1965, Hoogstraal 1985, Manilla 1998). Shelters and hosts of this species are usually located in lowland, deserts, semideserts, and dry tracts in cultivated zones, but rarely in humid biotopes (Morel 1965, Hoogstraal 1985). In only one site (Jbel El Hnoucha), situated in the subhumid zone in northern $\mathrm{Tu}$ nisia (site no. 1 in Table 1), O. normandi and O. erraticus were collected together in two burrows inhabited by $M$. shawi. However, all ticks from this site were free of Borrelia DNA and the Borrelia DNA detection was restricted to the $O$. erraticus collected in arid and Saharan zones. The most prevalent rodent species in Tunisia are $M$. shawi in the north and the center of the country and P. obesus in the center and the south (Bernard 1970, Fichet-Calvet et al. 2000). Indeed, these two species primarily inhabited the inspected burrows and our results suggest that they may be involved in the maintenance of Ornithodoros sp. in these areas and thus, possibly, 


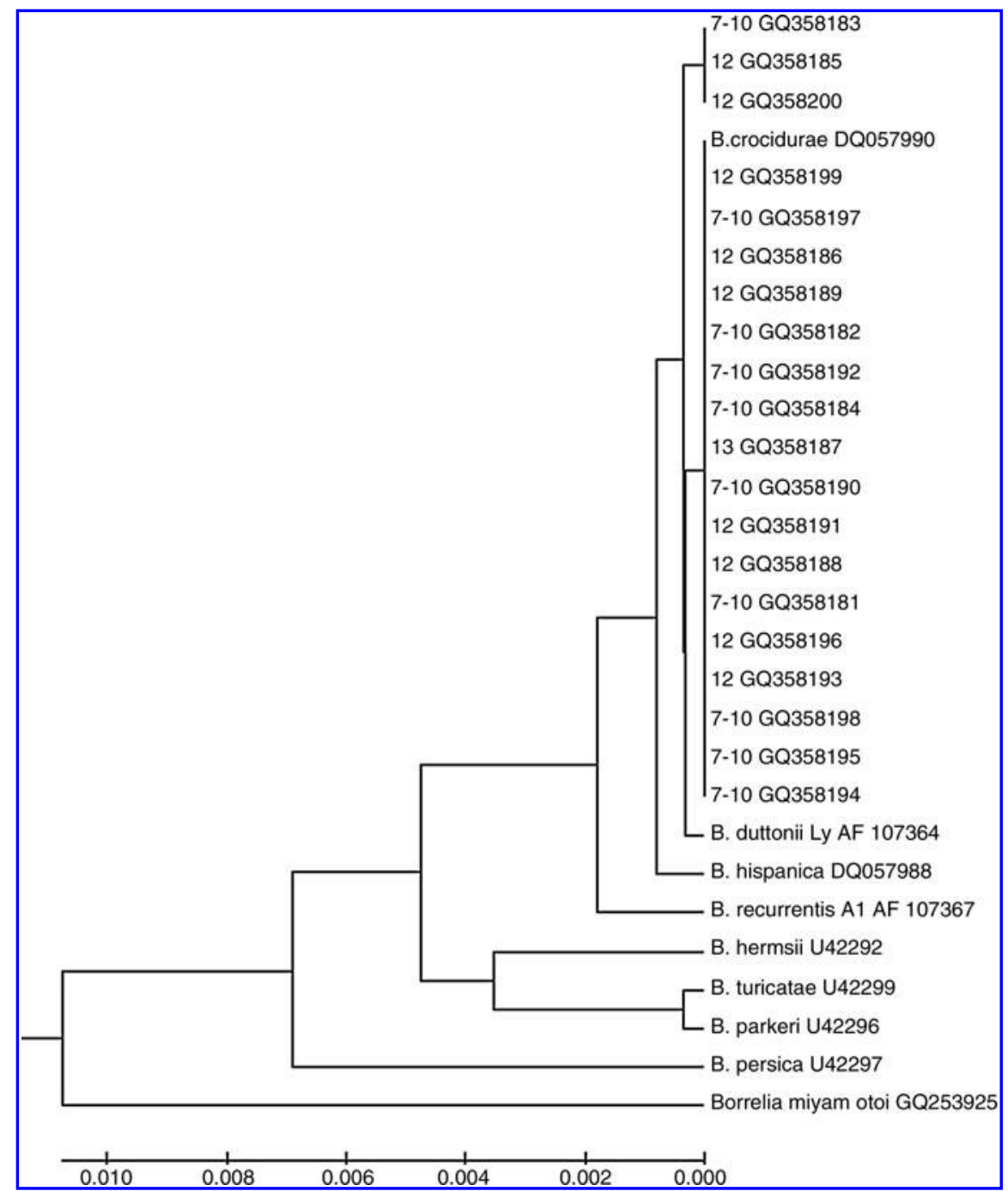

FIG. 2. Phylogenetic tree based on partial 16S rRNA sequences (1428 nt, position 43 to 1470) of 20 Borrelia crocidurae isolates from O. erraticus (small variety) collected in Tunisia. The tree was constructed by the unweighted pair group with mathematical average method, using a pairwise deletion procedure, and distances were calculated with the Jukes and Cantor method. Sequences are numbered beginning with the number of the site (Table 1) where the tick was collected (no distinction was made between sites 7,8,9, and 10) followed by the GenBank accession number.

in TBRF transmission. These results confirm the previous study that reported the detection of Borrelia sp. in $8 \%$ of blood samples collected from $P$. obesus captured in the central area of Tunisia (Fichet-Calvet et al. 2000).

In this study, we showed that sequencing the IGS region provided a high level of resolution for B. crocidurae, as for other species of relapsing fever Borrelia, with the exception of the complex B. duttonii/B. recurrentis, which cannot be separated by the IGS sequences, as previously shown (Scott et al. 2005, Sarih et al. 2009). B. crocidurae TBRF is common in West Africa where it is considered as a major cause of morbidity with a reported prevalence rate of 10\% (Trape et al. 1996). In Senegal, Mauritania, and Mali, the average infection rate of the vector, O. sonrai, was $31 \%$ (Vial et al. 2006). In Tunisia, B. crocidurae relapsing fever has been endemic and may have been responsible for epidemic relapsing fever in North Africa in the wake of Word War II (Nicolle et al. 1932, Hoogstraal 1985). Surprisingly, for the last few decades, no report on TBRF was recorded in this country. Here we showed that amplification of B. crocidurae DNA was successful from $15.1 \%$ of O. erraticus (small variety). The reported rate of $O$. sonrai infected by $B$. crocidurae in West Africa was higher than the one we estimated in $O$. erraticus in southern Tunisia (Vial et al. 2006). This difference may reflect either a difference in vector competence of each tick species or a variable abundance and infection of the mammalian reservoirs. Nevertheless, the B. crocidurae infection rate of ticks obtained in our study highlights the risk of TBRF transmission in southern Tunisia and our results confirm that $O$. erraticus (small variety) may be involved in B. crocidurae transmission in Tunisia and may infect humans. The human disease is probably underdiagnosed and neglected in Tunisia partly because of the low sensitivity of the direct microscopic analysis of blood samples, which is the only diagnostic test available in most clinical laboratories. In addition, transmission is expected to occur mainly in rural 


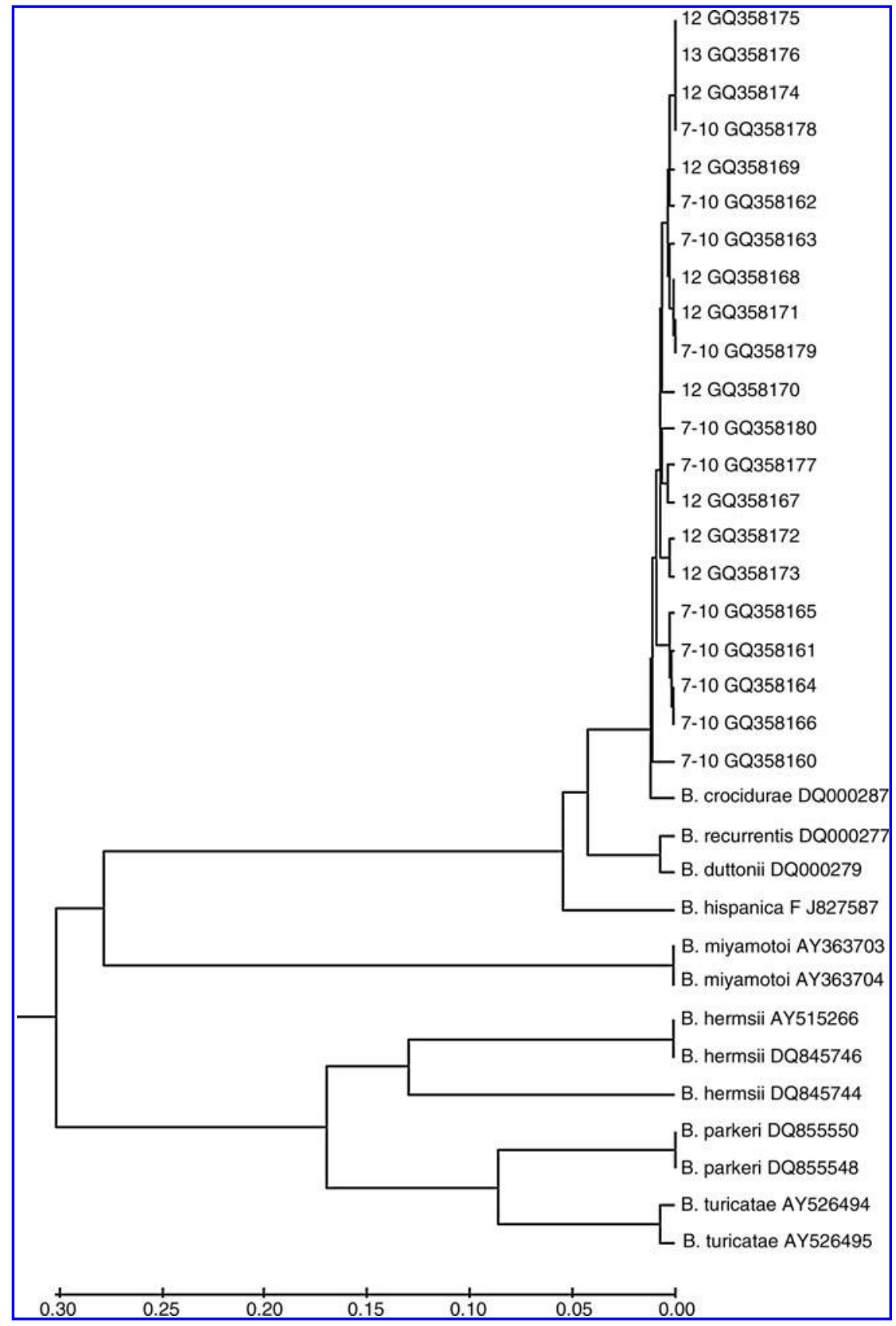

FIG. 3. Phylogenetic tree based on noncoding 16S-23S intergenic spacer sequences of 21 B. crocidurae isolates from O. erraticus (small variety) collected in Tunisia. The tree was constructed by the unweighted pair group with mathematical average method, using a pairwise deletion procedure, and distances were calculated with the Jukes and Cantor method. Sequences are numbered beginning with the number of the sampling site (Table 1) (no distinction was made between sites 7 , 8,9 , and 10) followed by the GenBank accession number.

settings where human hosts have likely, if any, more contact with the tick vector. Rural community does not necessarily attend health facilities because of distance and also because of the mild severity of the B. crocidurae infection. In Morocco, TBRF due to $B$. hispanica still occurs and may be attributed in part to the vector behavior (Sarih et al. 2009). Indeed, $O$. marocanus, vector of $B$. hispanica, infests stables and pens of domestic animals, whereas $O$. erraticus lives in the immediate vicinity of rodent burrows, limiting contact with human hosts (Hoogstraal 1985).
Climate change (drought and temperature increase) may lead to the colonization of new areas in North Africa by $O$. erraticus, which acts as vector of B. crocidurae. Indeed, drought is reported as responsible for a considerable spread of tick-borne borreliosis in West Africa (Trape et al. 1996). Therefore, our results suggest the possibility of an underdiagnosis and neglected occurrence of TBRF in Tunisia and should lead to clinical studies to evaluate the incidence of TBRF in this country and to establish a surveillance of the emergence of this disease. 


\section{Acknowledgments}

We are grateful to A. Rhim for his help in field work. We also thank Dr G. Uilenberg and A. Ghram for constructive comments on early drafts of the manuscript. We are also grateful to François Rodhain for his expert help and his kind revision of the manuscript. This work was supported by grant from the Réseau International des Instituts Pasteur (ACIP, 2004), le Ministère de l'enseignement supérieur, de la recherche scientifique et de la technologie de Tunisie and the University of Neuchâtel.

\section{Disclosure Statement}

No competing financial interests exist.

\section{References}

Assous, MV, Wilamowski, A, Bercovier, H, Marva, E. Molecular characterization of tickborne relapsing fever Borrelia, Israel. Emerg Infect Dis 2006; 12:1740-1743.

Bernard, J. Clef de détermination des rongeurs de Tunisie. Arch Inst Pasteur Tunis 1970; 47:265-307.

Bunikis, J, Garpmo, U, Tsao, J, Berglund, J, et al. Sequence typing reveals extensive strain diversity of the Lyme borreliosis agents Borrelia burgdorferi in North America and Borrelia afzelii in Europe. Microbiology 2004; 150:1741-1755.

Colas-Belcour, J. Sur l'identité d'Ornithodorus erraticus Lucas et d'Ornithodorus marocanus Vélu. Arch Inst Pasteur Tunis 1930; T19, 1:1-12.

Cutler, SJ. Possibilities for relapsing fever reemergence. Emerg Infect Dis 2006; 12:369-374.

Cutler, SJ, Abdissa, A, Trape, JF. New concepts for the old challenge of African relapsing fever borreliosis. Clin Microbiol Infect 2009; 15:400-406.

Cutler, SJ, Fekade, D, Hussein, K, Knox, KA, et al. Successful in vitro cultivation of Borrelia recurrentis. Lancet 1994; 342: 1213-1215.

Fichet-Calvet, E, Jomâa, I, Ben Ismail, R, Ashford, RW. Patterns of infection of haemoparasites in the fat sand rat, Psammomys obesus, in Tunisia, and effect on the host. Ann Trop Med Parasitol 2000; 94:55-68.

Fukunaga, M, Ushijima, Y, Aoki, Y, Talbert, A. Detection of Borrelia duttonii, a tick-borne relapsing fever agent in Central Tanzania within ticks by flagellin gene-based nested polymerase chain reaction. Vector Borne Zoonot Dis 2001; 1:331-338.

Hoogstraal, H. Argasid and nuttalliellid ticks as parasites and vectors. In Baker, JR, Muller, R, eds. Advances in Parasitology, vol. 24. London: Academic Press, 1985:135-283.

Kumar, S, Tamura, K, Nei, M. MEGA: Molecular Evolutionary Genetics Analysis software for microcomputers. Bioinformatics 1994; 10:189-191.

Larrousse, F. Présence au Kef (Tunisie) d'une nouvelle espèce du genre Ornithodoros: O. normandi N. sp. Ann Parasitol 1923; T.1, 2: 170-177.
Manilla, G. Genere Ornithodoros. In: Calderini, ed. Fauna d'Italia, Acari Ixodida. Academia Nazionale Italiana di Entomologia; Bologna, Italy 1998:55-63.

Marti Ras, N, Lascola, B, Postic, D, Cutler, SJ, et al. Phylogenesis of relapsing fever Borrelia spp. Int J Syst Bacteriol 1996; 46:859_ 865.

Morel, PC. Les tiques d'Afrique et du Bassin Méditerranéen. 1965. (In CD-ROM CIRAD (ed.) Montpellier, France; Centre International de la Recherche Agronomogia et du Developpment, 2003.

Nicolle, C, Anderson, C, Laigret, J. Etude des trois premiers cas de fièvre récurrente hispano-africaine observés en Tunisie et, plus spécialement, de leurs virus. Arch Inst Pasteur Tunis 1932; 21:43-72.

Parola, P, Raoult, D. Ticks and tick-borne bacterial diseases in humans: an emerging infectious threat. Clin Infect Dis 2001; 32:897-928.

Saitou, N, Nei, M. The neighbour-joining method: a new method for reconstructing phylogenetic trees. Mol Biol Evol 1987; 4:406-425.

Sarih, M, Garnier, M, Boudebouch, N, Bouattour, A, et al. Molecular detection of Borrelia hispanica tick-borne relapsing fever in Morocco. Emerg Infect Dis 2009; 10:1626-1629.

Scott, JC, Wright, DJ, Cutler, SJ. Typing African relapsing fever spirochetes. Emerg Infect Dis 2005; 11:1722-1729.

Sneath, PH, Sokal, RR. Numerical taxonomy. Nature 1962; 193:855-860.

Stanek, G. Borreliosis and travel medicine. J Travel Med 1995; 2:244-251.

Thompson, JD, Gibson, TJ, Plewniak, F, Jeanmougin, F, Higgins, DG. The ClustalX windows interface flexible strategies for multiple sequence alignment aided by quality analysis tools. Nucleic Acids Res 1997; 24:4876-4882.

Trape, JF, Duplantier, JM, Bouganali, H, Godeluck, B, et al. Tickborne borreliosis in West Africa. Lancet 1991; 337:473-475.

Trape, JF, Godeluck, B, Diatta, G, Rogier, C, et al. The spread of tick-borne borreliosis in West Africa and its relationship to sub-Saharan drought. Am J Trop Med Hyg 1996; 54:289-293.

Vial, L, Diatta, G, Tall, A, B, et al. Incidence of tick-borne relapsing fever in west Africa: longitudinal study. Lancet 2006; 1:37-43.

Wyplosz, B, Mihaila-Amrouche, L, Baixench, MT, Bigel, ML, et al. Imported tickborne relapsing fever, France. Emerg Infect Dis 2005; 11:1801-1803.

Address correspondence to: Ali Bouattour

Laboratoire d'Entomologie Médicale Institut Pasteur de Tunis

13, Place Pasteur Tunis Tunis 1002

Tunisia

E-mail: ali.bouattour@pasteur.rns.tn 